\title{
Ozone Therapy in the Management of Persistent Radiation-Induced Rectal Bleeding in Prostate Cancer Patients
}

\author{
Bernardino Clavo, ${ }^{1,2,3,4,5}$ Norberto Santana-Rodriguez, ${ }^{3,4}$ Pedro Llontop, ${ }^{3}$ \\ Dominga Gutierrez, ${ }^{1,4}$ Daniel Ceballos, ${ }^{6}$ Charlin Méndez, ${ }^{3}$ Gloria Rovira, ${ }^{7}$ \\ Gerardo Suarez, ${ }^{1,4}$ Dolores Rey-Baltar, ${ }^{1,4}$ Laura Garcia-Cabrera, ${ }^{1}$ \\ Gregorio Martínez-Sánchez, ${ }^{8}$ and Dolores Fiuza ${ }^{3}$
}

${ }^{1}$ Radiation Oncology, Dr. Negrin University Hospital, 35.010 Las Palmas, Spain

${ }^{2}$ Chronic Pain, Dr. Negrin University Hospital, 35.010 Las Palmas, Spain

${ }^{3}$ Experimental Surgery-Research Unit, Dr. Negrin University Hospital, 35.010 Las Palmas, Spain

${ }^{4}$ Canary Islands Institute for Cancer Research (ICIC), 35.010 Las Palmas, Spain

${ }^{5}$ Spanish Group for Clinical Research in Radiation Oncology (GICOR), Madrid, Spain

${ }^{6}$ Gastroenterology, Dr. Negrin University Hospital, 35.010 Las Palmas, Spain

${ }^{7}$ Ozone Therapy Unit, Quiron Hospital, 08.023 Barcelona, Spain

${ }^{8}$ Medical Center Beauty Benefit-San Biagio di Osimo, Osimo, 60.027 Ancona, Italy

Correspondence should be addressed to Bernardino Clavo; bernardinoclavo@gmail.com

Received 21 May 2015; Revised 24 June 2015; Accepted 30 June 2015

Academic Editor: Olumayokun A. Olajide

Copyright (C) 2015 Bernardino Clavo et al. This is an open access article distributed under the Creative Commons Attribution License, which permits unrestricted use, distribution, and reproduction in any medium, provided the original work is properly cited.

Introduction. Persistent radiation-induced proctitis and rectal bleeding are debilitating complications with limited therapeutic options. We present our experience with ozone therapy in the management of such refractory rectal bleeding. Methods. Patients $(n=12)$ previously irradiated for prostate cancer with persistent or severe rectal bleeding without response to conventional treatment were enrolled to receive ozone therapy via rectal insufflations and/or topical application of ozonized-oil. Ten (83\%) patients had Grade 3 or Grade 4 toxicity. Median follow-up after ozone therapy was 104 months (range: 52-119). Results. Following ozone therapy, the median grade of toxicity improved from 3 to $1(p<0.001)$ and the number of endoscopy treatments from 37 to $4(p=0.032)$. Hemoglobin levels changed from $11.1(7-14) \mathrm{g} / \mathrm{dL}$ to $13(10-15) \mathrm{g} / \mathrm{dL}$, before and after ozone therapy, respectively $(p=0.008)$. Ozone therapy was well tolerated and no adverse effects were noted, except soft and temporary flatulence for some hours after each session. Conclusions. Ozone therapy was effective in radiation-induced rectal bleeding in prostate cancer patients without serious adverse events. It proved useful in the management of rectal bleeding and merits further evaluation.

\section{Introduction}

Of the possible complications secondary to radiotherapy (RT) for prostate cancer, rectal bleeding $(\mathrm{RB})$ is one of the most relevant. The incidence and severity of late effects of RT depend on dosimetry factors (total dose of RT, rectal volume exposed to high doses, and 2D versus 3D conformation), fractionation (fractions of RT dose administered each day), technique for radiotherapy delivery (external beam radiotherapy versus brachytherapy), and patient factors (such as previous inflammatory colitis disease, vascular diseases as in diabetes which could adversely affect the healing process, and antiaggregant or anticoagulant treatments which can encourage bleeding $[1,2])$. With previous and current, external beam RT, Grade 3 or Grade 4 rectal toxicity has been described as occurring in between 1\% [3] and 5\% [4] of cases, with this percentage increasing up to $32 \%$ at 5 years (if Grade 2 or higher toxicities are included) [4]. With brachytherapy as well, Grade 2 and Grade 1 rectal toxicities at 5\% and 1\%, respectively, have been described [5]. Hence, radiation proctitis and $\mathrm{RB}$ remain relevant side effects following treatment of this tumor. 
TABLE 1: Clinical characteristics of the patients in the study prior to initiation of ozone therapy.

\begin{tabular}{|c|c|c|c|c|c|c|}
\hline Patient & Age & LHB & $\mathrm{HB}$ & Blood transfusion & Endoscopic treatments & Toxicity score \\
\hline$\# 1$ & 73 & 7.4 & 8 & 5 & 3 & 4 \\
\hline$\# 2$ & 74 & 6.6 & 7 & 4 & 5 & 3 \\
\hline \#3 & 69 & 5.6 & 7 & 3 & 4 & 3 \\
\hline$\# 4^{*}$ & 67 & 5 & 12 & 0 & 0 & 4 \\
\hline$\# 5$ & 66 & 7.3 & 11 & 1 & 0 & 3 \\
\hline \#6 & 64 & 12.7 & 14 & 0 & 5 & 3 \\
\hline \#7 & 73 & 6.1 & 7 & 2 & 5 & 3 \\
\hline \#8 & 70 & 11.6 & 12 & 0 & 0 & 2 \\
\hline$\# 9$ & 69 & 6.5 & 8 & 11 & 4 & 4 \\
\hline$\# 10$ & 73 & 11.8 & 12 & 0 & 0 & 3 \\
\hline$\# 11$ & 68 & $\mathrm{NA}^{* *}$ & $\mathrm{NA}^{* *}$ & 0 & 10 & 3 \\
\hline$\# 12$ & 77 & 14 & 14 & 0 & 1 & 2 \\
\hline
\end{tabular}

Note: LHB: lowest hemoglobin value (in $\mathrm{g} / \mathrm{dL}$ ) prior to initiation of ozone therapy.

$\mathrm{HB}$ : hemoglobin level in $\mathrm{g} / \mathrm{dL}$ prior to the initiation of ozone therapy.

* Patient \#4 was a referral for surgery from a different hospital, and details of previous blood transfusion and therapeutic endoscopy were not available.

**NA: patient \#11 did not have anemia, but the precise hemoglobin value had not been recorded.

Toxicity grade was according to the National Cancer Institute Common Terminology Criteria for Adverse Events (CTCAE) grading system (version 4.0): available from http://evs.nci.nih.gov/ftp1/CTCAE/CTCAE_4.03_2010-06-14_QuickReference_5x7.pdf.

In a large study of 32465 patients, complications other than incontinence or erectile dysfunction after treatment of localized prostate cancer had a 5-year cumulative incidence of admission-to-hospital of 22\%. Most hospital admissions in prostate cancer patients treated surgically were for urinary obstruction whereas, in patients treated with radiotherapy, the highest number of hospital admissions was for radiation proctitis [6]. Mild symptoms of radiation proctitis may remit spontaneously (without specific therapy) or with medical treatments involving endoscopy interventions. When RB becomes severe or persistent despite consecutive endoscopy procedures, treatment options become limited and as many as $5 \%$ of patients can become transfusion-dependent [2]. Hyperbaric oxygen (HBO) is the most-documented alternative therapy [7]. However, it needs extensive facilities since the equipment is cumbersome, it is of limited availability in most centers, and it has potential side effects such as claustrophobia, headache, vomiting, convulsions, and risk of barotrauma (ears, sinuses, and lung) [8]. Major surgical intervention is restricted, usually, to the most severe or lifethreatening conditions because of the potential morbidity and mortality [9].

Although their mechanisms of actions are different, several effects of ozone therapy $\left(\mathrm{O}_{3} \mathrm{~T}\right)$ have been observed that are similar to that associated with $\mathrm{HBO}[10]$. A century ago a description was published on how local $\mathrm{O}_{3} \mathrm{~T}$ application could improve radiation-induced side effects [11], and rectal $\mathrm{O}_{3}$ insufflations were described a couple of decades later [10]. We have published successful management of several radiation-induced toxicities using $\mathrm{O}_{3} \mathrm{~T}$ [12-15]. The aim of this current report is to present the effect of ozone therapy in the management of persistent radiation-induced $\mathrm{RB}$ in prostate cancer patients.

\section{Materials and Methods}

Patients $(n=12)$ with persistent RB were evaluated and underwent $\mathrm{O}_{3} \mathrm{~T}$ between April 2004 and October 2008.
Median age was 70 years (range: $64-77$ ). $\mathrm{O}_{3} \mathrm{~T}$ has been used over several years in our hospital (Chronic Pain Unit and Radiation Oncology Department) for complementary treatment for wound healing, ischemic syndromes, and pain. Without hyperbaric oxygen facilities in our hospital, $\mathrm{O}_{3} \mathrm{~T}$ was administered on compassionate grounds in these patients with persistent symptoms despite conventional management. All patients provided informed written consent to the therapy and all procedures conformed to the Helsinki Declaration of 1975. All patients had prostate cancer and had been receiving treatment between the years 2002 and 2008. The patients' data are summarized in Table 1.

Radiation proctitis diagnosis was by endoscopy in all patients and additional rectal biopsy in 5 patients. Prior to $\mathrm{O}_{3} \mathrm{~T}$, all patients were under conservative management including high-fiber diet and laxatives, oral or rectal drugs (sucralfate, mesalazine, or corticosteroid), and/or endoscopy procedures (argon laser, formalin, and coagulation). In the most severe cases, antiaggregating agents were temporarily withdrawn.

Severity of rectal hemorrhage was classified (Table 2) according to the National Cancer Institute Common Terminology Criteria for Adverse Events (CTCAE) grading system (version 4.0) [16].

2.1. Ozone Therapy Procedure. Our procedures for $\mathrm{O}_{3} \mathrm{~T}$ application in radiation proctitis have been described previously [14] and conform to international guidelines of the "Madrid Declaration on Ozone Therapy" [17]. These consisted of two different techniques: rectal insufflations of $\mathrm{O}_{3} / \mathrm{O}_{2}$ gas mixture (applied in 11 patients) and topical application of ozonized-oil (in 8 patients).

For rectal insufflations, an accurate concentration of $\mathrm{O}_{3} / \mathrm{O}_{2}$ gas mixture $\left(\mu \mathrm{g} / \mathrm{mL}\right.$ : $\mu \mathrm{g}$ of $\mathrm{O}_{3}$ per $\mathrm{mL}$ of $\mathrm{O}_{2}$ ) was obtained from clinical grade oxygen using a medical ozone generator (Ozonosan Alpha-plus, Dr. Hänsler GmbH, Iffezheim, Germany). Standard rectal cannula and $60 \mathrm{~mL}$ 
TABLE 2: Rectal hemorrhage grading according to CTCAE* .

\begin{tabular}{|c|c|c|c|c|}
\hline Grade & Criteria & Before $\mathrm{O}_{3} \mathrm{~T}$ & End $\mathrm{O}_{3} \mathrm{~T}$ & Last follow-up \\
\hline 0 & No symptoms & 0 & 5 & 7 \\
\hline 1 & Mild; intervention not indicated & 0 & 7 & 5 \\
\hline 2 & Moderate symptoms; medical intervention or minor cauterization indicated & 2 & 0 & 0 \\
\hline 3 & Transfusion, radiologic, endoscopic, or elective operative intervention indicated & 7 & 0 & 0 \\
\hline 4 & Life-threatening consequences; urgent intervention indicated & 3 & 0 & 0 \\
\hline
\end{tabular}

Note: CTCAE toxicity grade was significantly decreased at the end of $\mathrm{O}_{3} \mathrm{~T}(p<0.002)$ and at the last follow-up $(p<0.002)$ compared to that before $\mathrm{O}_{3} \mathrm{~T}$. Overall, the change in CTCAE toxicity grade was statistically significant $(p<0.001)$.

*According to the National Cancer Institute Common Terminology Criteria for Adverse Events (CTCAE) grading system (version 4.0): available from http://evs.nci.nih.gov/ftp1/CTCAE/CTCAE_4.03_2010-06-14_QuickReference_5x7.pdf.

silicone syringes were used for rectal insufflation. According to patient tolerance to the bowel distension (or bloating) insufflation gas volume was between 150 and $300 \mathrm{~mL}$ for each session. We followed the concept "start low, go slow" [18]. $\mathrm{O}_{3}$ concentrations at the first session were $5 \mu \mathrm{g} / \mathrm{mL}$ in 5 patients and $10 \mu \mathrm{g} / \mathrm{mL}$ in 6 patients. The concentration was progressively increased to $20 \mu \mathrm{g} / \mathrm{mL}$ in all patients and increased further to $30 \mu \mathrm{g} / \mathrm{mL}$ in 4 patients. Overall, most sessions were performed at an $\mathrm{O}_{3}$ concentration of $20 \mu \mathrm{g} / \mathrm{mL}$, with an insufflated gas volume of $180-240 \mathrm{~mL}$ and with total $\mathrm{O}_{3}$ administration between 3600 and $4800 \mu \mathrm{g}$ of $\mathrm{O}_{3}$ in each session. In one patient (patient \#5) 2 sessions of $50 \mu \mathrm{g} / \mathrm{mL}$ (and $60-100 \mathrm{~mL}$ ) were administered at the time of more intense bleeding. Ozone therapy was initially scheduled for 3 times/week. When patients showed clinical improvement (the decrease in the frequency and intensity of the bleeding being maintained), the number of sessions was progressively reduced to 2 sessions and 1 session/week, followed by 2 sessions/month and, finally, 1 session/month for 2-3 additional months. Time spent for each $\mathrm{O}_{3} \mathrm{~T}$ session of rectal insufflation was around 15-20 minutes. It is important to note that the production and administration of ozone need to be performed in situ in the outpatient clinic because $\mathrm{O}_{3}$ as a gas spontaneously decomposes to $\mathrm{O}_{2}$ with a half-life of 40 minutes at $20^{\circ} \mathrm{C}[10]$.

Topical ozonized-oil was applied in 8 patients. Commercial ozonized-oil (Dr. Hänsler GmbH, Iffezheim, Germany) was mixed in our hospital's pharmacy with liquid-Vaseline to provide ozonized-oil; concentrations ranged from 14 to $25 \%$. The $25 \%$ mixture (5 to $10 \mathrm{~mL}$ ) was administered 1-2 times/day, initially. When patients showed clinical improvement, the $\mathrm{O}_{3}$ concentration and the frequency of administration were progressively reduced. Since the half-life of ozonized-oil can range from months to years (depending on storage temperature), this approach allows self-administration at home and was especially relevant for patients residing a considerable distance away from our center.

Endoscopy requirements were at the discretion of the attending gastroenterologist.

$\mathrm{O}_{3} \mathrm{~T}$ was well tolerated and no adverse effects were noted, except soft and temporary flatulence for some hours after each session.

2.2. Statistical Analyses. The SPSS software package (version 15 for Windows) was used for all statistical analysis. Nonparametric tests were used for all comparisons because most variables were "nonnormally" distributed. Values are presented as median (range: minimum-maximum). Comparisons of paired data before and after therapy were with two-tailed Wilcoxon signed-rank test and Friedman's test for comparisons of related data at the 3 time-points before $\mathrm{O}_{3} \mathrm{~T}$, after $\mathrm{O}_{3} \mathrm{~T}$, and at final follow-up clinical visit. Correlations were assessed using Spearman's correlation coefficient (rho). Comparisons of categorical values were with the $\chi^{2}$ test. Statistical significance was set at $p<0.05$.

\section{Results}

Median time-lapse between the end of radiotherapy and rectal bleeding was 3 months (range: $0-34$ ). Median timelapse between the onset of rectal bleeding and commencing $\mathrm{O}_{3} \mathrm{~T}$ was 10 months (range: 2-23). Time-lapse between the end of radiotherapy and commencing $\mathrm{O}_{3} \mathrm{~T}$ was 16 months (range: 8-36). Median duration of $\mathrm{O}_{3} \mathrm{~T}$ was 13 months (range: $3-19$ ). The median number of $\mathrm{O}_{3} \mathrm{~T}$ sessions was 38 (range: 14107).

Half of the patients had needed blood transfusions before $\mathrm{O}_{3} \mathrm{~T}$ commencement and 26 blood transfusions had been administered (median: 3; range: 1-11). The lowest hemoglobin value before $\mathrm{O}_{3} \mathrm{~T}$ was a median of $7.3 \mathrm{~g} / \mathrm{dL}$ (range: 5-14). Median hemoglobin value just before $\mathrm{O}_{3} \mathrm{~T}$ commencement was $11.1 \mathrm{~g} / \mathrm{dL}$ (range: $7-14$ ) and 9 patients (75\%) were anemic. At the end of $\mathrm{O}_{3} \mathrm{~T}$, only 4 patients (33\%) were anemic compared to pre- $\mathrm{O}_{3} \mathrm{~T}$ values $(p=0.101)$ and the median hemoglobin value was $13 \mathrm{~g} / \mathrm{dL}$ (range: $10-15) \mathrm{g} / \mathrm{dL}(p=$ 0.008).

Before commencing $\mathrm{O}_{3} \mathrm{~T}$, a total number of 37 (median 4; range $0-10$ ) unsuccessful endoscopy treatments had been performed in 8 patients (67\%). The endoscopy was reduced to 17 procedures in 4 patients (median 0 ; range $0-8 ; p=\mathrm{NS}$ ) during $\mathrm{O}_{3} \mathrm{~T}$ and to 4 procedures in 2 patients during followup (median 0 ; range $0-2 ; p=0.015$ ). Overall, the change in the number of endoscopy treatments applied was statistically significant $(p=0.032)$.

The median CTCAE toxicity grade was 3 (range: $2-4$ ) before $\mathrm{O}_{3}$ T; it was reduced to 1 (range: 0-1) by the end of $\mathrm{O}_{3} \mathrm{~T}$ $(p=0.002)$ and to 0 (range: $0-1)$ at the last outpatient clinic follow-up $(p<0.002)$. Overall, the change in CTCAE toxicity grade was statistically significant $(p<0.001)$ (Table 2$)$.

CTCAE toxicity grade before $\mathrm{O}_{3} \mathrm{~T}$ was inversely correlated with time-lapse between the end of radiotherapy and rectal bleeding $(\mathrm{rho}=-0.588, p=0.044)$ and showed a trend 
towards a borderline significant direct correlation with $\mathrm{O}_{3} \mathrm{~T}$ duration (rho $=0.574, p=0.051$ ) and number of rectal $\mathrm{O}_{3} \mathrm{~T}$ sessions ( $\mathrm{rho}=0.648, p=0.059$ ); that is, higher toxicity grade was related to earlier commencement of $\mathrm{RB}$ and longer treatment with $\mathrm{O}_{3} \mathrm{~T}$. Toxicity grade before $\mathrm{O}_{3} \mathrm{~T}$ also showed an inverse trend towards a correlation with the lowest hemoglobin levels reached by the patient prior to $\mathrm{O}_{3} \mathrm{~T}$ commencement (rho $=-0.563, p=0.078$ ); that is, the greater the toxicity grades, the lower the hemoglobin levels.

Duration of $\mathrm{O}_{3} \mathrm{~T}$ (rectal insufflations and/or ozonizedoil) was significantly higher in younger patients ( $\mathrm{rho}=0.602$, $p=0.038)$.

Four of the 12 patients (33\%) were receiving antiaggregant treatment, and this showed a trend (albeit not statistically significant) towards a correlation with a higher requirement for blood transfusions before $\mathrm{O}_{3} \mathrm{~T}$ ( rho $=0.606, p=0.063$ ).

Median follow-up after $\mathrm{O}_{3} \mathrm{~T}$ was 104 months (range: 52119). Median follow-up after RT was 136 months (range: 69149). No patient had died from prostate cancer during followup period. Two patients (patient \#2 and patient \#3) died without evidence of tumor or biochemical relapse at 52 and 65 months after the end of $\mathrm{O}_{3} \mathrm{~T}$. Both patients were under antiaggregant treatment for vascular comorbidities and in both cases death was secondary to persistent and refractory radiation-induced hematuria. Only one patient (patient \#6) showed biochemical progression (33 months after the end of RT) with one isolated bone metastasis being noted. This patient was treated with RT for the bone metastasis and started permanent hormonal blockade without further biochemical relapse, or evidence of tumor, at the last followup 7 years later.

\section{Discussion}

Of the possible complications secondary to radiotherapy for prostate cancer, radiation proctitis is not unusual, although assessment and quantification of the different symptoms are not easy. We have used the CTCAE toxicity scales focusing on hemorrhagic symptoms. After $\mathrm{O}_{3} \mathrm{~T}$, there was a significant, and clinically relevant, decrease in CTCAE toxicity grade: median grade toxicity was decreased from Grade 3 to Grade 1 before and after $\mathrm{O}_{3} \mathrm{~T}$, with all patients achieving Grade 0 or Grade 1 toxicity status by the end of follow-up. These findings concur with results described with $\mathrm{HBO}$ where the improvement achieved was stable (or tended towards further improvement) throughout follow-up [7]. Quality-of-life is an important issue in cancer patients and this is even more relevant for those tumors where a longer survival, as is usually the case with prostate cancer, can be offered. At the end of $\mathrm{O}_{3} \mathrm{~T}$ the perception recorded by the patients in our study group was $100 \%$ improvement in 7 patients $(58 \%),>75 \%$ in 3 patients (25\%), and an improvement of around 50\% for the other 2 patients.

Proctitis management depends on the severity of symptoms. Grade 1 radiation proctitis usually remits spontaneously without specific therapy within 6 months in about 1 out of 3 patients [8]. First-level treatment includes laxatives, rectal or oral anti-inflammatory drugs (mesalazine, sulfasalazine, or glucocorticosteroids), and sucralfate [19] or sodium butyrate enemas [20]. Second-level treatment includes coagulation via endoscopy using bipolar or heater probes [21] or argon plasma and formaldehyde application for the more persistent symptoms $[22,23]$. Third-level treatment includes $\mathrm{HBO}$ [24]. Its beneficial effect has been confirmed by a double-blind randomized clinical trial [7] but it is not readily available in most hospitals. Finally, the last option is surgery, which is reserved for the most adverse clinical conditions because it is often associated with higher morbidity; that is, radiation-induced damage leading to $\mathrm{RB}$ is also associated with potential altered healing after surgery [2]. Several treatment-algorithms for RB secondary to chronic radiation proctopathy have been proposed $[2,25]$. Over the years, we have used several of these first- and/or second-level treatments in our patients.

The systemic effects of $\mathrm{O}_{3} \mathrm{~T}$ augur well for its use in the management of chronic radiation proctitis. Chronic radiation proctitis results from lesions in the connective tissues and blood vessels, leading to chronic ischemia and persistent prooxidative status with/without additional inflammation [26]. $\mathrm{O}_{3} \mathrm{~T}$ can improve hemorheological parameters [27], blood flow, and oxygenation in hypoxic tissues $[15,28,29]$ and can induce a beneficial modulation of the immuneinflammatory response [10]. Additionally, these vascular effects of $\mathrm{O}_{3} \mathrm{~T}$ widen its usefulness in combination with $\mathrm{HBO}$ (if/when available) because the high arterial $\mathrm{pO}_{2}$ levels obtained by $\mathrm{HBO}$ tend to induce vasoconstriction while the $\mathrm{O}_{3} \mathrm{~T}$ mitigates this effect.

Ozone does not act on specific receptors; its main mechanism of action is indirect, that is, by the production of a "controlled and moderate" oxidative stress which induces subsequent adaptive responses $[30] . \mathrm{O}_{3}$ reacts rapidly with antioxidants and polyunsaturated fatty acids (PUFA). The results are lipid oxidation products and induction of intracellular second messengers, of which the most important are hydrogen peroxide $\left(\mathrm{H}_{2} \mathrm{O}_{2}\right)$ and alkenals (mainly 4-hydroxynonenal, 4HNE) [31]. These second messengers lead to the activation of nuclear transcriptional factors such as nuclear factor(erythroid-derived 2) like 2 (Nrf2) which results in the transcription of antioxidant response elements (ARE) and subsequent production of antioxidant enzymes including superoxide dismutase, glutathione-peroxidase, heat shock proteins (HSP-70), and heme oxygenase-1 (HO-1) [31-33]. Additionally, Nrf2 can lead to suppression of nuclear factor kappa $\mathrm{B}(\mathrm{NF} \kappa \mathrm{B})$ which has a proinflammatory effect. By producing a controlled oxidative stress, $\mathrm{O}_{3} \mathrm{~T}$ can modulate the immune response by suppressing $\mathrm{NF} \kappa \mathrm{B}$ and inducing other nuclear transcription factors such as nuclear factor of activated T-cells (NFAT) and activated protein-1 (AP-1), as well as further modulation of interferons and interleukins [34].

Ozone does not have a linear dose-response relationship but follows the concept of "hormesis" in which a dose high enough to induce an adaptive response needs to be used but not sufficiently high to be harmful [18]. The molecular mechanisms of action of $\mathrm{O}_{3}$ have been described in recent reviews $[10,18,30,32,33,35]$. Chronic ischemia, oxidative stress, and inflammation are usually present in tissues in the course of radiation-induced side effects. As mentioned 
above, $\mathrm{O}_{3} \mathrm{~T}$ can modulate these factors. Hence, $\mathrm{O}_{3} \mathrm{~T}$ could be a valuable adjuvant in the management of radiation proctitis as has been documented for the use of corticosteroids (antiinflammatory effect), vitamin $\mathrm{E}$ and vitamin $\mathrm{C}$ [36], or vitamin $\mathrm{E}$ with pentoxifylline [37] (antioxidant effect) or acting against ischemia/hypoxia using $\mathrm{HBO}$ or pentoxifylline $[7,37]$. Indeed, $\mathrm{O}_{3} \mathrm{~T}$ could enhance the effect of $\mathrm{HBO}$ by decreasing $\mathrm{HBO}$-associated vasoconstriction secondary to hyperoxia and, as such, enhancing the effects of other medical or endoscopic treatments deployed in these patients.

Some reports have indicated success of local $\mathrm{O}_{3} \mathrm{~T}$ applications in radiation-induced toxicity [11-14]. In our study group, rectal $\mathrm{O}_{3}$ insufflations provided systemic and local effect and topical application of ozonated-oil provided an additional local effect. The ozonated-oil does not penetrate through the mucous membranes but, instead, reacts with PUFA to induce cellular production of hydrogen peroxide and alkenals which act as second messengers in improving wound healing $[38,39]$. The beneficial effect of ozonated-oil in radiation proctitis is currently supported by a preclinical study where ozonated-oil decreased macroscopic and pathological findings of acute radiation proctitis in rats [40]. These findings concur with a similar beneficial effect described in bisphosphonate-induced osteonecrosis of the jaw in cancer patients $[41,42]$. The last interesting property of the local application of $\mathrm{O}_{3} \mathrm{~T}$ for the management of $\mathrm{RB}$ and radiation proctitis is its bactericidal properties [38, 39], an effect that has been exploited in the treatment of public drinking water in many cities. The use of antianaerobic antibiotic metronidazole in radiation proctitis follows this rationale [43].

Clarke et al. [7] reviewed randomized studies using $\mathrm{HBO}$ in 120 patients for the treatment of radiation-induced proctitis. Many of the patients included in the studies had received HBO for nonbleeding symptoms. Of note was that only 14 patients were male, despite the study representing one of the largest works in the field. Our results compare favorably even though all our patients had been treated for rectal bleeding, symptoms that imply more advanced toxicity $(83 \%$ had Grade 3 or Grade 4 toxicity) and, consequently, poorer outcomes expected. Our patients had had a high requirement for endoscopy treatments and blood transfusions. For example, therapeutic endoscopy had been received by 8 of the 12 patients (67\%) in our study. Mayer et al. described a group of 10 prostate cancer patients with radiation proctitis treated with HBO. The patients represented $60 \%$ with Grade 3 and none with Grade 4 toxicity, and only $30 \%$ had undergone previous treatment with laser coagulation [24].

The number of $\mathrm{O}_{3} \mathrm{~T}$ sessions required for successful treatment of radiation-induced $\mathrm{RB}$ depends on the individual patient. In our study, the median number of treatment sessions was 38 (range: 14-107) and is similar to reports using HBO. The review by Clarke et al. [7] of randomized studies showed a median number between 20 and 80 HBO sessions, while the study by Mayer et al. [24] reported a median of 30 HBO sessions (range: 13-60).

Our study has several limitations. This is a noncontrolled study and, as such, the existence of some bias or subjective influence cannot be excluded. Similarly, there is the uncertainty regarding the real impact on the clinical evolution of the symptoms resulting from not having the $\mathrm{O}_{3} \mathrm{~T}$ administered. However, $83 \%$ of the patients in our study had persistent Grade 3 or Grade 4 toxicity despite conventional treatment. This would have presented questionable ethics of not offering an option (potentially therapeutic or palliative) that was available in our center, an experimental study of radiation proctitis with a control group having described the beneficial effect of the ozone treatment [40]. Another important limitation of the study is the limited sample size. However, many studies in this field have similar sample sizes, and most of the studies with larger sample sizes had enrolled males as well as females and with different tumors and, as such, with different radiation doses. All patients in our study were irradiated for prostate carcinoma at similar high doses of radiation (70-74 Gy), that is, higher than in other pelvic tumors (gynecological, bladder, or rectal tumors).

Finally, it needs to be highlighted in our study that the median follow-up after $\mathrm{O}_{3} \mathrm{~T}$ was 104 months (range: 52119 ), which is considerably longer than the median followup reported in other studies: 12 months (range: 8-27) [24] or 2 years (3-60 months) [7]. The significant and clinically relevant decrease in the grade of toxicity following $\mathrm{O}_{3} \mathrm{~T}$ was maintained for this protracted follow-up period of 104 months and is of considerable benefit to the patient.

In conclusion, our results show a significant, and clinically relevant, effect of ozone therapy in the management of radiation-induced rectal bleeding. Following ozone therapy, the requirements for blood transfusions were significantly decreased as was the need for endoscopic procedures. The grades of toxicity (according to the CTCAE scale) were also reduced. These effects were maintained over the course of protracted follow-up, and no adverse impact on survival was noted. We believe the local application of ozone therapy can be useful as adjuvant treatment in managing radiation proctitis and, as such, merits further evaluation in randomized clinical trials.

\section{Disclosure}

Preliminary data were presented at the "International Meeting of the Madrid Declaration on Ozone Therapy (Second Edition): Towards an United Approach to the Practice of Ozone Therapy Worldwide," Madrid (Spain), June 2015.

\section{Conflict of Interests}

The authors have no conflict of interests to report.

\section{Acknowledgments}

Activities related with this work have been supported, in part, by I3SNS Program from the Carlos III Institute of Health (Instituto de Salud Carlos III; Grants INT 07/030 and INT 07/172), Madrid, Spain. The ozone therapy device Ozonosan Alpha-plus and ozonized-oil were provided by Dr. Hänsler GmbH (Iffezheim, Germany). The authors are grateful to Dr. Maria A. Hernandez (Department of Radiation Oncology, 
Dr. Negrin University Hospital) and Dr. Francisco Robaina (Chronic Pain Unit, Dr. Negrin University Hospital) for help with patient management and ozone treatment. The authors thank the Pharmacy Department in their hospital, in which the commercial ozonized-oil was processed to provide them with a range of appropriate concentrations for use in this study. Editorial assistance was by Dr. Peter R. Turner of $t$ SciMed (Reus, Spain).

\section{References}

[1] K. S. Choe, A. B. Jani, and S. L. Liauw, "External beam radiotherapy for prostate cancer patients on anticoagulation therapy: how significant is the bleeding toxicity?" International Journal of Radiation Oncology Biology Physics, vol. 76, no. 3, pp. 755-760, 2010.

[2] R. Stacey and J. T. Green, "Nonendoscopic therapies for the management of radiation-induced rectal bleeding," Current Opinion in Supportive and Palliative Care, vol. 7, no. 2, pp. 175182, 2013.

[3] A. Zapatero, A. Guerrero, X. Maldonado et al., "High-dose radiotherapy with short-term or long-term androgen deprivation in localised prostate cancer (DART01/05 GICOR): a randomised, controlled, phase 3 trial," The Lancet Oncology, vol. 16, no. 3, pp. 320-327, 2015.

[4] S. T. H. Peeters, W. D. Heemsbergen, P. C. M. Koper et al., "Dose-response in radiotherapy for localized prostate cancer: results of the Dutch multicenter randomized phase III trial comparing 68 Gy of radiotherapy with 78 Gy," Journal of Clinical Oncology, vol. 24, no. 13, pp. 1990-1996, 2006.

[5] M. J. Zelefsky, Y. Yamada, X. Pei et al., "Comparison of tumor control and toxicity outcomes of high-dose intensitymodulated radiotherapy and brachytherapy for patients with favorable risk prostate cancer," Urology, vol. 77, no. 4, pp. 986993, 2011.

[6] R. K. Nam, P. Cheung, S. Herschorn et al., "Incidence of complications other than urinary incontinence or erectile dysfunction after radical prostatectomy or radiotherapy for prostate cancer: a population-based cohort study," The Lancet Oncology, vol. 15, no. 2, pp. 223-231, 2014.

[7] R. E. Clarke, L. M. Tenorio, J. R. Hussey et al., "Hyperbaric oxygen treatment of chronic refractory radiation proctitis: a randomized and controlled double-blind crossover trial with long-term follow-up," International Journal of Radiation Oncology, Biology, Physics, vol. 72, no. 1, pp. 134-143, 2008.

[8] M. L. Rodríguez, M. M. Martín, L. C. Padellano, A. M. Palomo, and Y. I. Puebla, "Gastrointestinal toxicity associated to radiation therapy," Clinical and Translational Oncology, vol. 12, no. 8, pp. 554-561, 2010.

[9] K. M. Greven and T. Paunesku, "Radiation complications of the pelvis," in Radiation Toxicity: A Practical Guide, W. J. Samll and G. E. Woloschak, Eds., pp. 125-153, Springer Science+Business Media, New York, NY, USA, 2008.

[10] V. Bocci, E. Borrelli, V. Travagli, and I. Zanardi, "The ozone paradox: ozone is a strong oxidant as well as a medical drug," Medicinal Research Reviews, vol. 29, no. 4, pp. 646-682, 2009.

[11] G. Stoker, "The surgical uses of ozone," The Lancet, vol. 26, p. 797, 1917.

[12] B. Clavo, D. Gutiérrez, D. Martín, G. Suárez, M. A. Hernández, and F. Robaina, "Intravesical ozone therapy for progressive radiation-induced hematuria," Journal of Alternative and Complementary Medicine, vol. 11, no. 3, pp. 539-541, 2005.
[13] B. Clavo, N. Santana-Rodriguez, S. M. López-Silva et al., "Persistent PORT-A-CATH-related fistula and fibrosis in a breast cancer patient successfully treated with local ozone application," Journal of Pain and Symptom Management, vol. 43, no. 2, pp. e3e6, 2012.

[14] B. Clavo, D. Ceballos, D. Gutierrez et al., "Long-term control of refractory hemorrhagic radiation proctitis with ozone therapy," Journal of Pain and Symptom Management, vol. 46, no. 1, pp. 106-112, 2013.

[15] B. Clavo, G. Suarez, Y. Aguilar et al., "Brain ischemia and hypometabolism treated by ozone therapy," Forschende Komplementärmedizin, vol. 18, no. 5, pp. 283-287, 2011.

[16] National Cancer Institute Common Terminology Criteria for Adverse Events (CTCAE) grading system (version 4.0), http:// evs.nci.nih.gov/ftp1/CTCAE/CTCAE_4.03_2010-06-14_QuickReference_5x7.pdf.

[17] The International Scientific Committee of Ozone Therapy, "Madrid declaration on ozone therapy," http://www.aepromo .org/declaracion_madrid/Madrid_declaration.pdf.

[18] V. A. Bocci, I. Zanardi, and V. Travagli, "Ozone acting on human blood yields a hormetic dose-response relationship," Journal of Translational Medicine, vol. 9, article 66, 2011.

[19] R. Kochhar, F. Patel, S. C. Sharma et al., "Radiation-induced proctosigmoiditis-prospective, randomized, double-blind controlled trial of oral sulfasalazine plus rectal steroids versus rectal sucralfate," Digestive Diseases and Sciences, vol. 36, no. 1, pp. 103-107, 1991.

[20] A. Hille, M. K. A. Herrmann, T. Kertesz et al., "Sodium butyrate enemas in the treatment of acute radiation-induced proctitis in patients with prostate cancer and the impact on late proctitis: a prospective evaluation," Strahlentherapie und Onkologie, vol. 184, no. 12, pp. 686-692, 2008.

[21] D. M. Jensen, G. A. Machicado, S. Cheng, M. E. Jensen, and R. Jutabha, "A randomized prospective study of endoscopic bipolar electrocoagulation and heater probe treatment of chronic rectal bleeding from radiation telangiectasia," Gastrointestinal Endoscopy, vol. 45, no. 1, pp. 20-25, 1997.

[22] G. Karamanolis, K. Triantafyllou, Z. Tsiamoulos et al., "Argon plasma coagulation has a long-lastingtherapeutic effect in patients with chronic radiation proctitis," Endoscopy, vol. 41, no. 6, pp. 529-531, 2009.

[23] E. M. Haas, H. R. Bailey, and I. Farragher, "Application of 10 percent formalin for the treatment of radiation-induced hemorrhagic proctitis," Diseases of the Colon and Rectum, vol. 50, no. 2, pp. 213-217, 2007.

[24] R. Mayer, H. Klemen, F. Quehenberger et al., "Hyperbaric oxygen-an effective tool to treat radiation morbidity in prostate cancer," Radiotherapy and Oncology, vol. 61, no. 2, pp. 151-156, 2001.

[25] G. Karamanolis, P. Psatha, and K. Triantafyllou, "Endoscopic treatments for chronic radiation proctitis," World Journal of Gastrointestinal Endoscopy, vol. 5, no. 7, pp. 308-312, 2013.

[26] M. Hauer-Jensen, J. Wang, and J. W. Denham, "Bowel injury: current and evolving management strategies," Seminars in Radiation Oncology, vol. 13, no. 3, pp. 357-371, 2003.

[27] R. Giunta, A. Coppola, C. Luongo et al., "Ozonized autohemotransfusion improves hemorheological parameters and oxygen delivery to tissues in patients with peripheral occlusive arterial disease," Annals of Hematology, vol. 80, no. 12, pp. 745-748, 2001.

[28] B. Clavo, L. Catala, J. L. Perez, V. Rodriguez, and F. Robaina, "Ozone therapy on cerebral blood flow: a preliminary report," 
Evidence-Based Complementary and Alternative Medicine, vol. 1, no. 3, pp. 315-319, 2004.

[29] B. Clavo, D. Fiuza, F. Robaina et al., "Effect of ozone therapy on muscle oxygenation," Journal of Alternative and Complementary Medicine, vol. 9, no. 2, pp. 251-256, 2003.

[30] L. Re, G. Malcangi, and G. MartinezSanchez, "Medical ozone is now ready for a scientific challenge: current status and future perspectives," Journal of Experimental and Integrative Medicine, vol. 2, pp. 193-196, 2012.

[31] A. Pecorelli, V. Bocci, A. Acquaviva et al., "NRF2 activation is involved in ozonated human serum upregulation of HO-1 in endothelial cells," Toxicology and Applied Pharmacology, vol. 267, no. 1, pp. 30-40, 2013.

[32] L. Re, G. Martínez-Sánchez, M. Bordicchia et al., "Is ozone preconditioning effect linked to Nrf2/EpRE activation pathway in vivo? A preliminary result," European Journal of Pharmacology, vol. 742, pp. 158-162, 2014.

[33] V. Bocci and G. Valacchi, "Nrf2 activation as target to implement therapeutic treatments," Frontiers in Chemistry, vol. 3, article 4, 2015.

[34] V. Bocci, Ozone. A New Medical Drug, Springer, Dordrecht, The Netherlands, 2nd edition, 2011.

[35] M. Sagai and V. Bocci, "Mechanisms of Action Involved in Ozone Therapy: is healing induced via a mild oxidative stress?" Medical Gas Research, vol. 1, no. 1, p. 29, 2011.

[36] M. Kennedy, K. Bruninga, E. A. Mutlu, J. Losurdo, S. Choudhary, and A. Keshavarzian, "Successful and sustained treatment of chronic radiation proctitis with antioxidant vitamins $\mathrm{E}$ and C," The American Journal of Gastroenterology, vol. 96, no. 4, pp. 1080-1084, 2001.

[37] A. Hille, H. Christiansen, O. Pradier et al., "Effect of pentoxifylline and tocopherol on radiation proctitis/enteritis," Strahlentherapie und Onkologie, vol. 181, no. 9, pp. 606-614, 2005.

[38] G. Valacchi, Y. Lim, G. Belmonte et al., "Ozonated sesame oil enhances cutaneous wound healing in SKH1 mice," Wound Repair and Regeneration, vol. 19, no. 1, pp. 107-115, 2011.

[39] G. Martínez-Sánchez, L. Re, G. Perez-Davison, and R. HorwatDelaporte, "Las aplicaciones médicas de los aceites ozonizados, actualización," Revista Española de Ozonoterapia, vol. 2, no. 1, pp. 121-139, 2012.

[40] F. A. Gültekin, B. H. Bakkal, D. Sümer, F. Köktürk, and S. Bektaş, "Effects of ozonated olive oil on acute radiation proctitis in rats," Balkan Medical Journal, vol. 30, no. 4, pp. 369-374, 2013.

[41] A. Agrillo, F. Filiaci, V. Ramieri et al., "Bisphosphonate-related osteonecrosis of the jaw (BRONJ): 5 year experience in the treatment of 131 cases with ozone therapy," European Review for Medical and Pharmacological Sciences, vol. 16, no. 12, pp. 17411747, 2012.

[42] C. I. Ripamonti, E. Cislaghi, L. Mariani, and M. Maniezzo, "Efficacy and safety of medical ozone $\left(\mathrm{O}_{3}\right)$ delivered in oil suspension applications for the treatment of osteonecrosis of the jaw in patients with bone metastases treated with bisphosphonates: preliminary results of a phase I-II study," Oral Oncology, vol. 47, no. 3, pp. 185-190, 2011.

[43] J. Cavcic, J. Turcic, P. Martinac et al., "Metronidazole in the treatment of chronic radiation proctitis: clinical trial," Croatian Medical Journal, vol. 41, no. 3, pp. 314-318, 2000. 


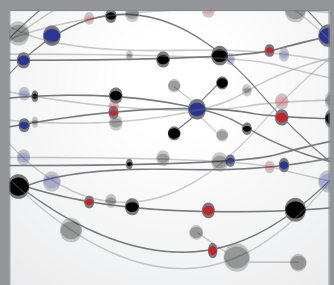

The Scientific World Journal
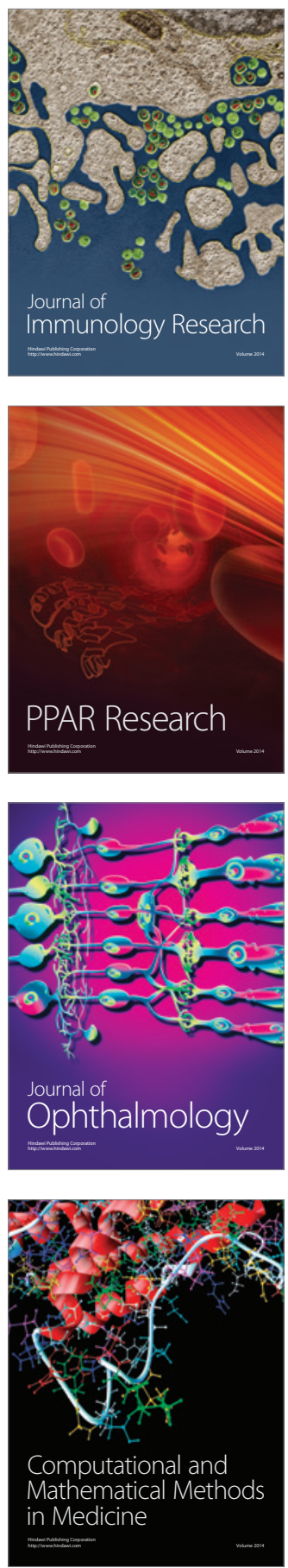

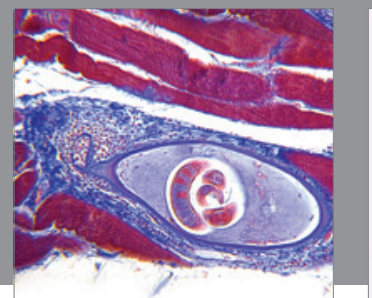

Gastroenterology

Research and Practice
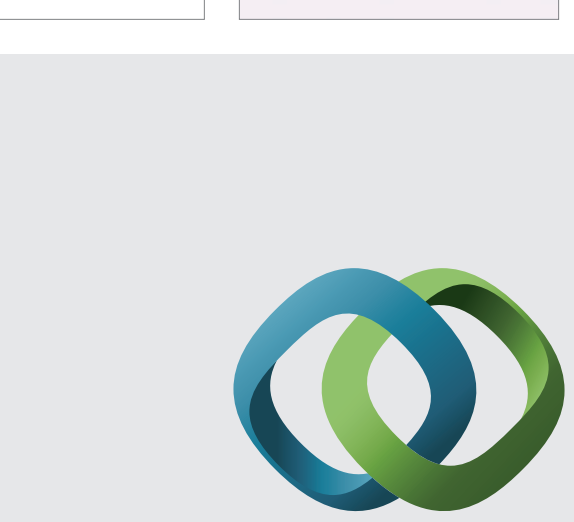

\section{Hindawi}

Submit your manuscripts at

http://www.hindawi.com
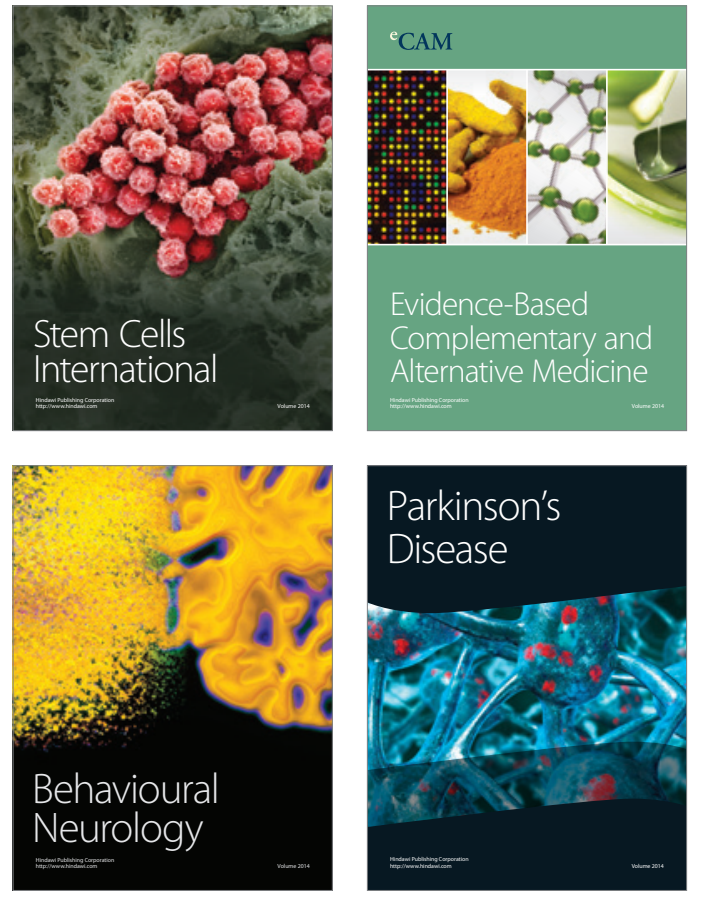
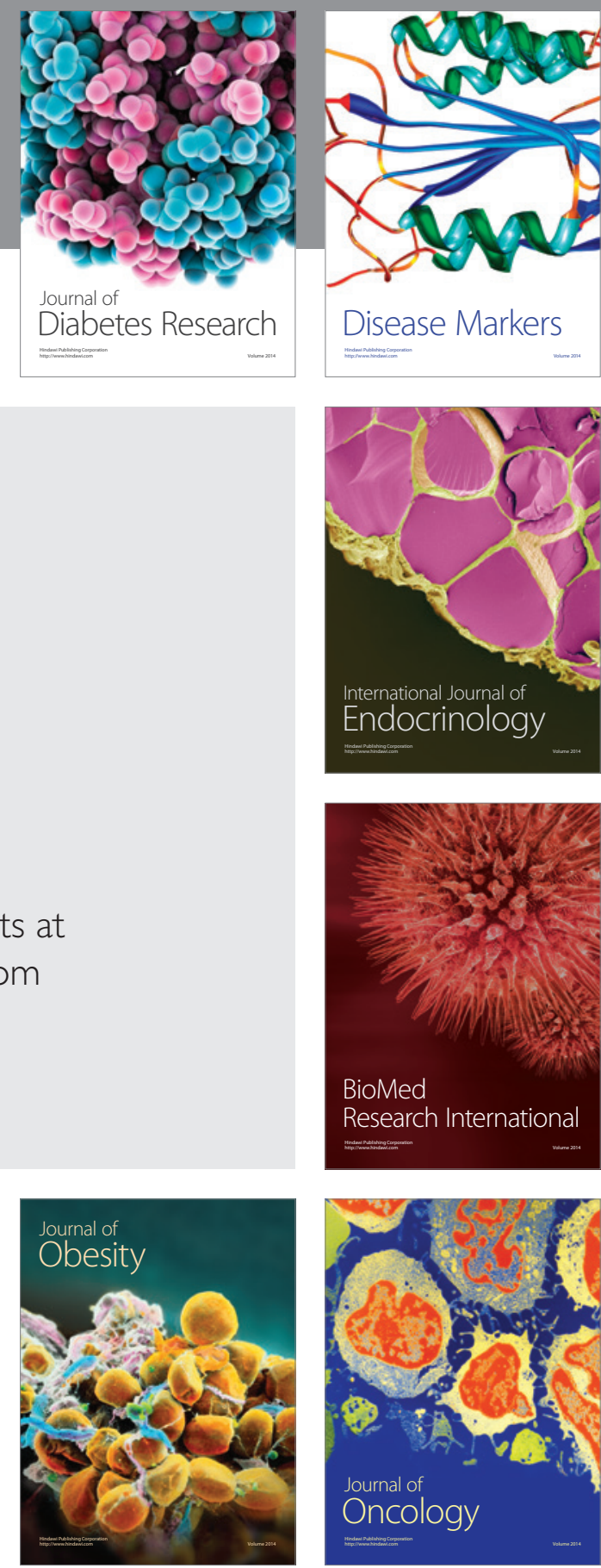

Disease Markers
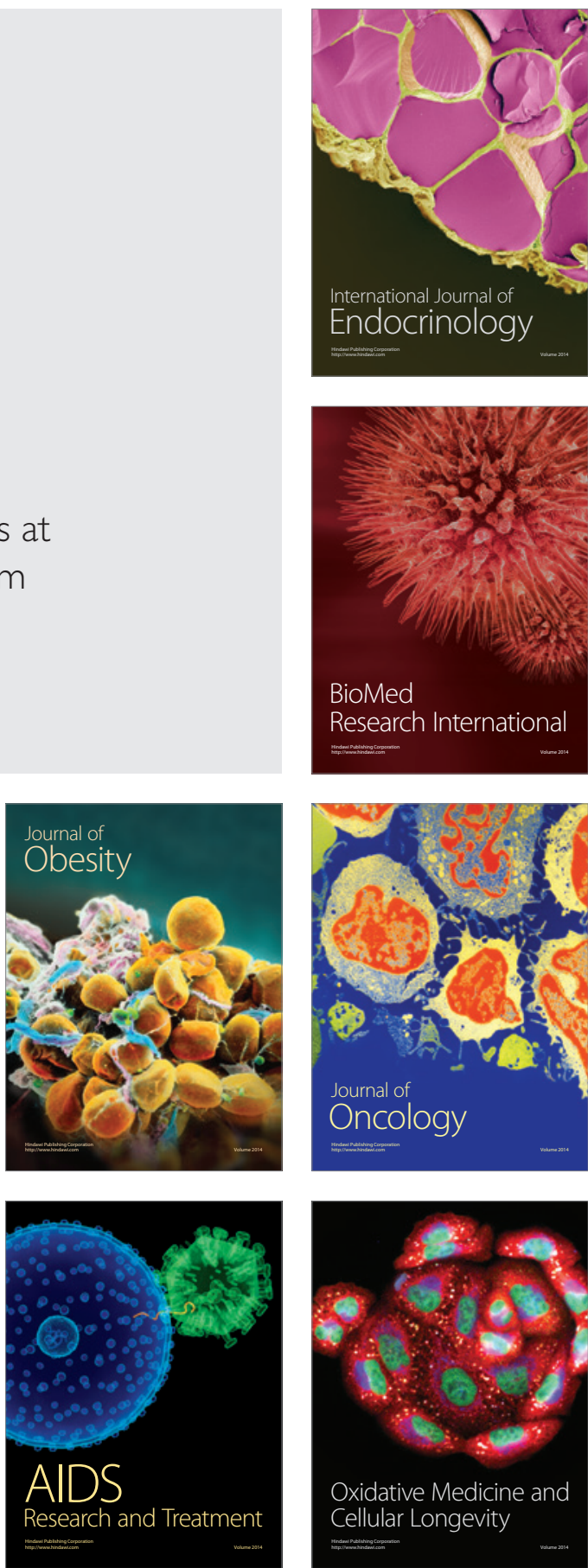